\title{
Chronic Inflammation as a Potential Predictive Factor of Nivolumab Therapy in Non-small Cell Lung Cancer
}

\author{
MARTIN SVATON ${ }^{1}$, MILADA ZEMANOVA $^{2}$, JANA SKRICKOVA ${ }^{3}$, LENKA JAKUBIKOVA ${ }^{3}$, \\ VITEZSLAV KOLEK ${ }^{4}$, JURAJ KULTAN ${ }^{4}$, LEONA KOUBKOVA ${ }^{5}$, ALZBETA BEJCKOVA ${ }^{5}$, \\ FRANTISEK SALAJKA ${ }^{6}$, MICHAL HRNCIARIK ${ }^{6}$, BOHUSLAV MELICHAR ${ }^{7}$, \\ DAVID VRANA $^{7}$, MAREK KONECNY $^{8}$, RENATA CHLOUPKOVA ${ }^{8}$ and MILOS PESEK ${ }^{1}$ \\ ${ }^{1}$ Department of Pneumology and Phthisiology, Charles University, \\ Faculty of Medicine in Pilsen, Pilsen, Czech Republic; \\ ${ }^{2}$ Department of Oncology, Charles University, First Faculty of Medicine in Prague, Prague, Czech Republic; \\ ${ }^{3}$ Department of Respiratory Diseases and TB, Faculty of Medicine, \\ Masaryk University, and University Hospital, Brno, Czech Republic; \\ ${ }^{4}$ Department of Pneumology and Phthisiology, Palacky University, \\ Faculty of Medicine and Dentistry, Olomouc, Czech Republic; \\ ${ }^{5}$ Department of Pneumology, Second Faculty of Medicine, \\ Charles University Prague and Faculty Hospital Motol, Prague, Czech Republic; \\ ${ }^{6}$ Department of Pneumology, Charles University, Faculty of Medicine in Hradec Kralove, Prague, Czech Republic; \\ ${ }^{7}$ Department of Oncology, Palacky University, Faculty of Medicine and Dentistry, Olomouc, Czech Republic; \\ ${ }^{8}$ Institute of Biostatistics and Analyses, Faculty of Medicine, Masaryk University, Brno, Czech Republic
}

\begin{abstract}
Aim: To investigate potential associations between clinical and standard peripheral blood biomarkers and clinical outcome in patients with non-small cell lung cancer (NSCLC) treated with nivolumab. Patients and Methods: A total of 120 patients with advanced NSCLC treated at seven comprehensive cancer care centers were analyzed in this national retrospective study. Survival statistics were evaluated using the KaplanMeier method and Cox analysis. Results: Among clinical parameters, histology was significantly associated with progression-free survival. Univariate Cox-proportional hazards model indicated prognostic and predictive role of a panel of laboratory parameters reflecting chronic inflammatory pattern (elevated neutrophil count, neutrophil-to-lymphocyte ratio, platelet-to-lymphocyte ratio, $C$-reactive protein and decrease in hemoglobin and albumin). Higher serum calcium concentration was also associated with nivolumab treatment effect. Conclusion: Tumor histology was the only clinical parameter predicting the outcome of nivolumab treatment.
\end{abstract}

Correspondence to: Martin Svaton, Department of Pneumology and Phthisiology, Charles University, Faculty of Medicine in Pilsen, E. Benese 13, 305 99, Pilsen, Czech Republic. Tel: +420 377402973, e-mail: svatonm@fnplzen.cz

Key Words: Nivolumab, non-small cell lung cancer, overall survival, progression-free survival, biomarker.
Among the laboratory parameters, our analysis identified a laboratory panel reflecting chronic inflammation as a potential predictive marker of nivolumab treatment.

Nivolumab is a human monoclonal anti-programed cell death 1 (PD-1) therapy that represents a new therapeutic option in the second-line treatment of advanced non-small cell lung cancer (NSCLC). Improved efficacy and a more favorable adverse event profile have been documented for nivolumab compared to docetaxel in phase III studies. However, the objective response rate on nivolumab monotherapy is only about $20 \%$, with the disease control rate reaching approximately $50 \%(1,2)$. Therefore, many patients do not benefit from nivolumab treatment and, taking into account the cost/efficacy ratio, identification of predictive parameters that would aid identification of the most suitable candidates for this therapy remains a topic of high unmet medical need. Much effort has been made to demonstrate that programmed death-ligand 1 (PD-L1) expression on tumor cells represent, a potential biomarker of response to anti-PD1 therapy $(3,4)$. However, for nivolumab, this seems to hold true in nonsquamous NSCLC only, although data for other drugs, e.g. pembrolizumab, have demonstrated the predictive role of PD-L1 expression even in patients with squamous histology (5). For various reasons, PD-L1 expression is still not an ideal biomarker (6). Therefore, the search for other predictive biomarkers should continue. Several approaches 
in this direction include, for example, gene-signature profiles, tumor mutation burden or neoantigen expression. In addition, biomarkers of immune response are being studied, leading to introduction of new methodologies in the clinical setting (7). Finally, the potential of routinely used clinical and biochemical biomarkers is also being examined (8). The advantage of parameters based on peripheral blood cell counts, or commonly determined biochemical parameters such as C-reactive protein (CRP) or serum albumin concentration is commonly used in patients with NSCLC in daily clinical practice at minimal cost. For NSCLC, the association between these parameters and nivolumab efficacy has not been well established. The objective of the present retrospective study was to investigate the association of selected clinical, hematological and biochemical parameters with the outcome of nivolumab treatment in a multicenter national study.

\section{Patients and Methods}

Study design and treatment. Clinical and laboratory data of patients with cytologically or histologically confirmed advanced NSCLC treated with nivolumab were retrospectively analyzed. The patients were treated in the second-or higher line of treatment in an Expanded Access Program provided by Bristol-Myers Squibb at seven Oncology and Pneumo-oncology Departments in the Czech Republic in 2015 and 2016. Nivolumab was administered intravenously at the approved dose of $3 \mathrm{mg} / \mathrm{kg}$ every 2 weeks. The treatment was administered until progression (or as long as the patient benefitted from the therapy according to the treating physician) or unacceptable toxicity for a maximum of 2 years. In the case of treatment-related toxicity, corticosteroid use or interruption of nivolumab were recommended. Clinical follow-up including physical examination, chest X-ray and routine laboratory tests were performed at least every 4 weeks; computed tomography (CT) or positron-emission tomography/CT were performed at regular intervals according to the routine practice of the center or when progression was suspected based on clinical or chest X-ray examination. Clinical parameters analyzed included age, sex, Eastern Cooperative Oncology Group performance status (ECOG PS), smoking status, histology, number of previous treatment lines, the extent of the disease at the time of treatment initiation and prior radiotherapy. Laboratory parameters investigated included total neutrophil, total lymphocyte, total eosinophil and platelet counts; hemoglobin, albumin, CRP, glucose, sodium, potassium and calcium concentrations; and lactate dehydrogenase (LDH) activity were measured at the start of therapy and after 2 months of therapy, i.e. on the day of the first nivolumab dose and 8 weeks later ( \pm 1 week) as part of routine blood check ups. Early Access Program was approved by the local Ethics Committee and all patients gave their informed consent.

Statistical methods. Categorical variables are described using absolute and relative frequencies. Survival analysis was calculated using the Kaplan-Meier method, and all point estimates were supplemented with 95\% confidence intervals (CI). Progression-free survival (PFS) was determined from the date of the initiation of nivolumab treatment to the date of the first documented radiological progression (by RECIST) (9) or death. Overall survival (OS) was determined from the date of initiation of nivolumab treatment to the date of death. The patients with no PFS or OS event were censored at the date of the last visit. Comparison of patient survival between different subgroups was performed with the log-rank test. Survival curves were plotted for all parameters with $p<0.05$.

The neutrophil-to-lymphocyte ratio (NLR) and platelet-tolymphocyte ratio (PLR) were also calculated, as well as calcium corrected for albumin (Ca-corr) according to the following formula: Ca-corr=Calcium (total) $+0.020 \times(41.3$-albumin $)$. Any changes in laboratory parameters between the two measurements (treatment initiation and 2 months later) were also investigated.

The associations of baseline clinical characteristics and laboratory parameters with OS and PFS were analyzed. The associations between laboratory parameters and OS and PFS were assessed as continuous variables, as well as dichotomous variables using a cut-off value (as normal values and above or below normal as appropriate for the respective parameter). Univariate Cox test of proportional risks was used to calculate differences in OS and PFS for laboratory parameters as continuous variables. Point estimates of hazard ratio (HR) are shown with $95 \%$ CI. Statistical significance of HR was calculated using the Wald test. Cut-offs were determined based on the upper or lower limits of normal values for laboratory parameters. A receiver operating characteristic (ROC) analysis was calculated to estimate the optimal cut-off values for NLR, PLR and Ca-corr, using a landmark of 6 months' survival from the initiation of treatment. The optimal cut-off was selected according to the criterion of maximizing the product of sensitivity and specificity.

A risk index (RI) was calculated in patients with complete records based on biomarkers of chronic inflammation associated with PFS/OS as defined by the univariate Cox test namely: elevated leucocyte and neutrophil counts, reduced lymphocyte count, elevated NLR, reduced hemoglobin, elevated LDH and CRP. The patients were divided into three subgroups according to the number of risk factors they had: low RI: 0-2 risk factors, medium RI: 3-4 risk factors, and high RI: $\geq 5$ risk factors. An ROC analysis was carried out to estimate the optimal cutoff values for parameters included in the RI.

A multivariate Cox proportional-hazards model was used to assess the effect of potential prognostic clinical factors, including the RI, sex, age, smoking status, histology, ECOG PS, the extent of disease at the time of treatment initiation and number of prior treatment lines on OS and PFS in patients with complete records. Hazard ratios (HR) were completed with $95 \%$ confidence intervals (CI), and the statistical significance of HR was assessed by the Wald test.

The decision on statistical significance was based on $\alpha=0.05$. Because of exploratory nature of the analysis, the Bonferroni correction was not performed.

\section{Results}

Patient characteristics. In total, 120 patients were included in the present retrospective analysis; 71 patients $(59.2 \%)$ were male. The majority of patients were smokers or exsmokers $(81.7 \%)$. Eighty patients had adenocarcinoma (66.7\%) and 40 squamous cell carcinoma (33.3\%). The baseline patient characteristics are summarized in Table I.

Clinical parameters. Patients with adenocarcinoma had significantly shorter PFS compared to patients with squamous carcinoma [median=3.7 (95\% CI=2.6-4.8) months vs. 6.8 
Table I. Baseline patient characteristics.

\begin{tabular}{lcc}
\hline Characteristic & $\mathrm{n}$ & $\%$ \\
\hline Gender & & \\
$\quad$ Male & 71 & 59.2 \\
Female & 49 & 40.8 \\
Smoking & & \\
$\quad$ Non-smoker & 22 & 18.3 \\
Former smoker & 43 & 35.8 \\
$\quad$ Smoker & 55 & 45.8 \\
Histology & & \\
Adenocarcinoma & 80 & 66.7 \\
Squamous cell carcinoma & 40 & 33.3 \\
\hline
\end{tabular}

(95\% CI 4.8-8.7) months, $p=0.013]$. Kaplan-Meier curves for PFS are shown in Figure 1. Sex, smoking status, age, extent of the disease at the time of treatment initiation, ECOG PS, the number of previous treatment lines and prior radiotherapy were not associated with PFS. None of the clinical parameters were associated with OS in the present study (Table II).

Laboratory parameters. Using a univariate Cox-proportional hazards model, we observed shorter PFS in patients with elevated neutrophil count, CRP and Ca-corr, and lower hemoglobin and albumin concentrations after 2 months of therapy. Shorter OS was associated with elevated neutrophil count, LDH and CRP and reduced hemoglobin at the start as well as after 2 months of therapy; and elevated NLR and platelet count at the start of therapy; elevated Ca-corr after 2 months of therapy; and reduced albumin after 2 months of therapy. The results are summarized in Table III.

When the results were evaluated based on dichotomization by limit of normal, patients with normal CRP concentration after 2 months of therapy had significantly longer PFS compared to patients with increased CRP. Improved PFS was also observed in patients with normal/increased lymphocyte count at the start of therapy, hemoglobin concentration after 2 months of therapy, Ca-corr at the start of therapy and lower CRP concentration after 2 months of therapy. Longer OS was also evident when evaluated in patients with normal/increased lymphocyte count and lower albumin and sodium concentrations at the start of therapy. When evaluated after 2 months of therapy, significantly improved OS was observed in patients with normal/lower neutrophil count, LDH activity and CRP concentration, and normal/increased hemoglobin. Higher NLR (cut-off value 3.8) and PLR (cut-off value 169.1) were significantly associated with lower OS, but not with PFS. Ca-corr under the cut-off value at the start of and after 2 months of therapy correlated with shorter OS and with shorter PFS when measured 2 months into therapy. The results are summarized in Table IV and Kaplan-Meier curves

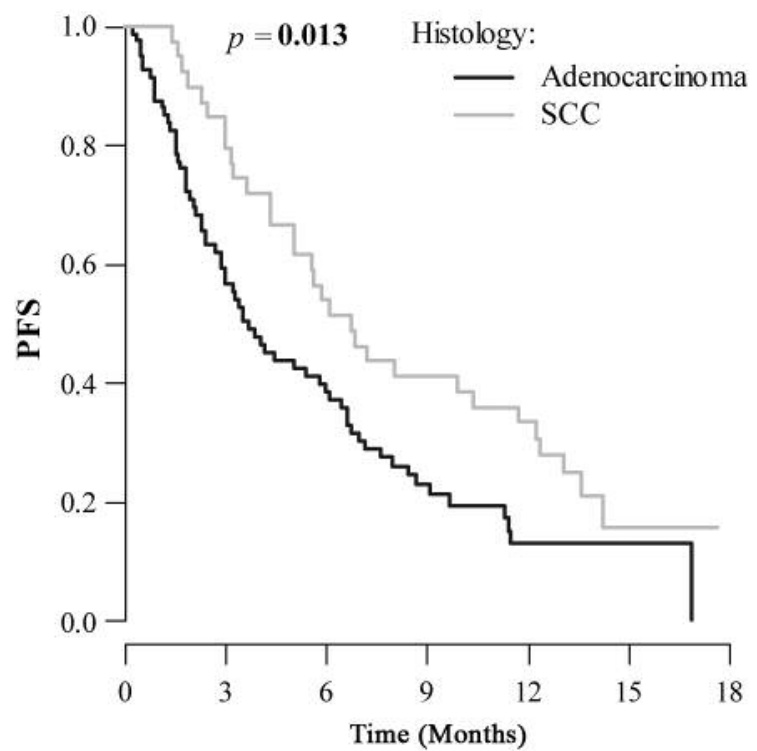

Figure 1. Progression-free survival (PFS) after nivolumab treatment initiation according to histology. SCC: Squamous cell carcinoma.

for statistically significant results are shown in Figure 2.

When changes to laboratory parameters between the two measurements were investigated, only patients with an increase in eosinophil count had significantly better OS compared to patients with stable or reduced counts. The results are summarized in Table $\mathrm{V}$.

When the patients were divided into three subgroups according to the RI, statistically significant differences were observed both in PFS and OS at the time of treatment initiation and also after 2 months of therapy. Higher RI was associated with shorter PFS and OS. The results are summarized in Table VI and Kaplan-Meier curves for statistically significant results are shown in Figure 3.

Multivariate Cox proportional-hazard model. In multivariate Cox proportional-hazard model, histology was confirmed as the only significant predictive clinical parameter for OS. OS was shorter in patients with adenocarcinoma compared to patients with squamous cell carcinoma $(\mathrm{HR}=2.23 ; p=0.045)$. None of the clinical parameters was associated with PFS. RI was associated with OS and also with PFS in patients with high RI ( $\geq 5$ factors; $H R=6.00$ and 2.20, $p<0.001$ and $p=0.034$, respectively) compared to patients with low RI ( $\leq 2$ risk factors; Table VI).

\section{Discussion}

The data from the present retrospective analysis identified a number of potential predictors of outcome in patients with NSCLC treated with nivolumab in second and higher lines 
Table II. Overall (OS) and progression-free (PFS) survival after nivolumab treatment initiation according to baseline characteristics.

\begin{tabular}{|c|c|c|c|c|c|}
\hline Characteristic & $\mathrm{n}$ & Median OS (95\% CI) & $p$-Value* & Median PFS (95\% CI) & $p$-Value* \\
\hline \multicolumn{6}{|l|}{ Gender } \\
\hline Male & 71 & $11.2(9.0-13.4)$ & \multirow[t]{2}{*}{0.188} & $5.7(4.2-7.2)$ & \multirow[t]{2}{*}{0.747} \\
\hline Female & 49 & $8.0(1.7-14.2)$ & & $3.7(1.9-5.4)$ & \\
\hline \multicolumn{6}{|l|}{ Smoking } \\
\hline Non-smoker & 22 & $4.9(0.1-10.5)$ & \multirow[t]{3}{*}{0.144} & $3.0(2.0-4.0)$ & \multirow[t]{3}{*}{0.178} \\
\hline Former smoker & 43 & $9.2(6.5-12.0)$ & & $5.4(3.3-7.5)$ & \\
\hline Smoker & 55 & $12.0(10.3-13.7)$ & & $5.9(3.7-8.0)$ & \\
\hline \multicolumn{6}{|l|}{ Histology } \\
\hline Adenocarcinoma & 80 & $9.2(5.7-12.8)$ & \multirow[t]{2}{*}{0.329} & $3.7(2.6-4.8)$ & \multirow[t]{2}{*}{0.013} \\
\hline Squamous cell carcinoma & 40 & $11.2(9.5-12.9)$ & & $6.8(4.8-8.7)$ & \\
\hline \multicolumn{6}{|c|}{ Radiotherapy before nivolumab treatment** } \\
\hline Yes & 21 & $7.3(1.7-13.0)$ & \multirow[t]{2}{*}{0.126} & $5.8(2.6-9.0)$ & \multirow[t]{2}{*}{0.399} \\
\hline No & 63 & $10.6(7.4-13.8)$ & & $3.7(1.7-5.6)$ & \\
\hline \multicolumn{6}{|c|}{ Age at initiation of nivolumab treatment } \\
\hline$\leq 65$ Years & 53 & $9.9(7.3-12.6)$ & \multirow[t]{2}{*}{0.411} & $4.1(2.3-6.0)$ & \multirow[t]{2}{*}{0.229} \\
\hline$>65$ Years & 67 & $11.2(8.3-14.1)$ & & $6.0(4.0-8.0)$ & \\
\hline \multicolumn{6}{|c|}{ Extent of the disease at treatment initiation } \\
\hline III A or III B & 16 & $12.6(11.6-13.6)$ & \multirow[t]{2}{*}{0.132} & $6.6(0.7-12.6)$ & \multirow[t]{2}{*}{0.074} \\
\hline IV & 104 & $9.9(7.3-12.5)$ & & $5.0(3.1-6.9)$ & \\
\hline \multicolumn{6}{|c|}{ ECOG PS at initiation of nivolumab treatment } \\
\hline 0 & 30 & $10.9(8.4-13.4)$ & \multirow[t]{2}{*}{0.416} & $6.1(2.2-9.9)$ & \multirow[t]{2}{*}{0.776} \\
\hline 1 & 90 & $10.6(7.5-13.7)$ & & $5.0(3.0-7.0)$ & \\
\hline \multicolumn{6}{|l|}{ Number of prior treatment lines } \\
\hline 1 & 47 & $10.7(8.8-12.6)$ & \multirow[t]{3}{*}{0.609} & $5.0(2.4-7.6)$ & \multirow[t]{3}{*}{0.948} \\
\hline 2 & 36 & $11.7(7.8-15.7)$ & & $5.4(3.5-7.3)$ & \\
\hline 3 or more & 37 & $10.6(5.8-15.4)$ & & $4.1(0.9-7.4)$ & \\
\hline
\end{tabular}

CI: Confidence intervaI; ECOG PS: Eastern Cooperative Oncology Group performance status. ${ }^{*}$ Log-rank test. $* *$ Only 84 patients had valid record for radiotherapy before nivolumab treatment.

of therapy. The tumor histology was a significant clinical predictor of outcome in the multivariate analysis of the present cohort of patients. Our proposed RI based on parameters associated with chronic inflammation may also be suggested for future prospective studies.

The results of previous studies examining different clinical parameters as potential predictors of immunotherapy outcome are inconsistent with regard to their results as well as regarding the studied tumor types, therapies and patient populations (10-16). In the present study, only histology was significantly associated with PFS. Studies in melanoma indicated a possible influence of ECOG PS, sex and age on OS and objective response rate in patients treated with PD1 inhibitors $(10,11)$. Older age might possibly be connected with increased levels of tumorsuppressive cells and female sex with improved function of T-helper cells (10). However, these results were not replicated in the present study. Some smaller studies suggest that histology (better response in patients with squamous histology) and worse performance (ECOG PS $\geq 2$ ) may affect nivolumab efficacy (12-16). Our analysis as well as some other studies did not confirm the effect of ECOG PS on survival (15-17). Although ECOG PS is a well-known prognostic factor for NSCLC, the present cohort did not include patients with PS $>1$, i.e. patients with significantly worse prognosis. Thus, only further data in patients with wider range of PS would address the predictive role of this parameter. However, it may be difficult to offer anti-PD1 therapy to patients with poor PS and this group of patients are usually highly selected with $\mathrm{PS} \geq 2$.

Better results for nivolumab observed in squamous cell NSCLC might be partly explained by higher mutational burden/neoantigen expression and consequently greater immunogenicity of these tumors (18). The present data also support this notion. Smoking history is another frequently discussed predictive parameter associated with increased mutational load of the tumor (18). Three smaller studies examining the predictive role of smoking history reported contradictory results $(12,14,16)$. However, meta-analysis of large clinical trials with checkpoint inhibitors indicates that a history of smoking is associated with the efficacy of immunotherapy (17). In the present study, only nonsignificant numerical differences indicating better PFS and OS in smokers were noted in the univariate analysis. This might be explained by the limited number of patients, in particular never smokers, in the present analysis. 
Svaton et al: Chronic Inflammation as Potential Predictive Factor of Nivolumab Response in NSCLC

Table III. Overall and progression-free survival results according to laboratory parameters using a univariable Cox proportional-hazards model*.

\begin{tabular}{|c|c|c|c|c|c|c|}
\hline \multirow[t]{2}{*}{ Laboratory parameter } & \multirow[t]{2}{*}{ Time point } & \multirow[t]{2}{*}{$\mathrm{N}$} & \multicolumn{2}{|c|}{ Overall survival } & \multicolumn{2}{|c|}{ Progression-free survival } \\
\hline & & & $\mathrm{HR}(95 \% \mathrm{CI})$ & $p$-Value & $\mathrm{HR}(95 \% \mathrm{CI})$ & $p$-Value \\
\hline \multirow[t]{2}{*}{ Neutrophil count** } & Initial & 120 & $1.094(1.008-1.186)$ & 0.032 & $1.033(0.964-1.108)$ & 0.359 \\
\hline & 2 Months & 106 & $1.210(1.104-1.327)$ & $<0.001$ & $1.098(1.019-1.182)$ & 0.014 \\
\hline \multirow[t]{2}{*}{ Lymphocyte count** } & Initial & 120 & $0.799(0.561-1.138)$ & 0.214 & $0.946(0.710-1.262)$ & 0.706 \\
\hline & 2 Months & 106 & $0.572(0.387-0.844)$ & 0.005 & $0.855(0.635-1.150)$ & 0.300 \\
\hline \multirow[t]{2}{*}{ Eosinophil count $* *$} & Initial & 120 & $0.833(0.224-3.094)$ & 0.785 & $1.329(0.576-3.063)$ & 0.505 \\
\hline & 2 Months & 106 & $0.346(0.094-1.273)$ & 0.110 & $0.815(0.473-1.405)$ & 0.462 \\
\hline \multirow[t]{2}{*}{ Hemoglobin } & Initial & 120 & $0.980(0.968-0.992)$ & 0.001 & $0.990(0.980-1.000)$ & 0.054 \\
\hline & 2 Months & 108 & $0.969(0.954-0.985)$ & $<0.001$ & $0.976(0.963-0.990)$ & 0.001 \\
\hline \multirow[t]{2}{*}{ Platelet count** } & Initial & 119 & $1.003(1.000-1.005)$ & 0.023 & $1.001(0.999-1.003)$ & 0.309 \\
\hline & 2 Months & 108 & $1.002(1.000-1.005)$ & 0.064 & $1.001(0.999-1.003)$ & 0.227 \\
\hline \multirow[t]{2}{*}{ Albumin } & Initial & 86 & $0.939(0.875-1.008)$ & 0.084 & $0.950(0.893-1.011)$ & 0.105 \\
\hline & 2 Months & 71 & $0.886(0.819-0.958)$ & 0.003 & $0.929(0.869-0.992)$ & 0.029 \\
\hline \multirow[t]{2}{*}{$\mathrm{LDH}$} & Initial & 70 & $1.382(1.101-1.736)$ & 0.005 & $1.200(0.978-1.471)$ & 0.080 \\
\hline & 2 Months & 64 & $1.249(1.093-1.427)$ & 0.001 & $1.127(0.995-1.276)$ & 0.060 \\
\hline \multirow[t]{2}{*}{ CRP } & Initial & 93 & $1.013(1.006-1.021)$ & $<0.001$ & $1.008(1.002-1.015)$ & 0.010 \\
\hline & 2 Months & 81 & $1.007(1.003-1.012)$ & 0.001 & $1.005(1.001-1.009)$ & 0.011 \\
\hline \multirow[t]{2}{*}{ Glucose } & Initial & 98 & $0.947(0.818-1.097)$ & 0.468 & $0.969(0.859-1.093)$ & 0.610 \\
\hline & 2 Months & 90 & $0.942(0.793-1.120)$ & 0.500 & $0.995(0.870-1.137)$ & 0.936 \\
\hline \multirow[t]{2}{*}{ Sodium } & Initial & 119 & $0.933(0.869-1.001)$ & 0.054 & $0.986(0.926-1.049)$ & 0.653 \\
\hline & 2 Months & 108 & $0.928(0.843-1.022)$ & 0.130 & $0.990(0.914-1.072)$ & 0.800 \\
\hline \multirow[t]{2}{*}{ Potassium } & Initial & 119 & $1.214(0.653-2.254)$ & 0.540 & $0.949(0.580-1.553)$ & 0.835 \\
\hline & 2 Months & 108 & $0.859(0.465-1.586)$ & 0.627 & $1.044(0.631-1.728)$ & 0.868 \\
\hline \multirow[t]{2}{*}{ Ca-corr } & Initial & 67 & $1.179(0.918-1.513)$ & 0.197 & $1.004(0.818-1.232)$ & 0.967 \\
\hline & 2 Months & 45 & $1.415(1.145-1.749)$ & 0.001 & $1.428(1.133-1.801)$ & 0.003 \\
\hline NLR & Initial & 120 & $1.044(1.001-1.088)$ & 0.043 & $1.033(0.985-1.083)$ & 0.185 \\
\hline PLR & Initial & 119 & $1.001(1.000-1.001)$ & 0.134 & $1.000(0.999-1.001)$ & 0.663 \\
\hline
\end{tabular}

Ca-corr: Corrected calcium; CI: confidence intervaI; CRP: C-reactive protein; LDH: lactate dehydrogenase; NLR: neutrophil-to-lymphocyte ratio; PLR: platelet-to-lymphocyte ratio. *Change of 0.1 was considered in the Cox model, continuous data were used. **Absolute.

Recent reports indicate potential synergy between radiotherapy and nivolumab (19). In the present retrospective analysis, information on radiotherapy was available in only two-thirds of patients and there was also a considerably different time between the administration of radiotherapy and the start of treatment with nivolumab. Therefore, it is not possible to come to a conclusion regarding any association between nivolumab treatment and the efficacy of radiotherapy. However, future studies should take into account the potential association between the end of radiotherapy and the onset of immunotherapy. The present data do indicate that nivolumab may be equally effective in elderly patients and in higher lines of therapy.

Biomarkers play an essential role in the management of patients with cancer (20). The present study follows similar investigations carried out in metastatic melanoma that represents, in many aspects, a model tumor for immunotherapy $(10,21)$. An indisputable advantage of biomarkers derived from peripheral blood cell counts is the practicality of routine use in contrast to expensive and laborious approaches such as the determination of the tumor mutational load (22).
Laboratory parameters, as possible predictive biomarkers of checkpoint inhibitors, were first investigated in patients with melanoma treated with ipilimumab and nivolumab. LDH, CRP and leukocyte counts (including eosinophils, lymphocytes and neutrophils) were suggested as potential biomarkers $(10,11,21,23,24)$. An association of $\mathrm{LDH}$ activity, CRP concentration and neutrophil counts with the efficacy of nivolumab might be explained by the tumor burden and potential effect on the function of tumorinfiltrating lymphocytes (25). These biomarkers were also investigated in patients with NSCLC. LDH, CRP, NLR, PLR, and neutrophil, lymphocyte and eosinophil counts have been associated with both OS and sometimes also with PFS in these studies $(8,12,15,16)$. However, the results between the studies were inconsistent. This might be caused by, on the one hand, often smaller sets of patients with retrospective data, but also by the different cut-offs used in these studies. The data indicated that the use of different cut-offs or the timing of measurement at the start or during the therapy may affect the results $(11,12,24)$. Therefore, in the present study we decided to use continuous variables for laboratory 
Table IV. Overall (OS) and progression-free (PFS) survival after nivolumab treatment initiation according to laboratory parameters (only statistically significant results are shown).

\begin{tabular}{|c|c|c|c|c|c|c|c|}
\hline Laboratory parameter & Timepoint & Value & $\mathrm{N}$ & $\begin{array}{c}\text { Median OS }(95 \% \mathrm{CI}), \\
\text { months }\end{array}$ & $p$-Value* & $\begin{array}{c}\text { Median PFS }(95 \% \mathrm{CI}), \\
\text { months }\end{array}$ & $p$-Value* \\
\hline \multirow[t]{2}{*}{ Neutrophil count } & \multirow[t]{2}{*}{2 Months } & $\leq$ Normal & 72 & $12.2(9.9-14.5)$ & \multirow[t]{2}{*}{0.013} & $6.8(5.3-8.2)$ & \multirow[t]{2}{*}{0.057} \\
\hline & & >Normal & 34 & $7.5(2.2-12.7)$ & & $4.1(2.1-6.2)$ & \\
\hline \multirow[t]{2}{*}{ Lymphocyte count } & \multirow[t]{2}{*}{ Initial } & $<$ Normal & 19 & $5.9(1.0-10.8)$ & \multirow[t]{2}{*}{0.003} & $3.2(2.7-3.8)$ & \multirow[t]{2}{*}{0.030} \\
\hline & & $\geq$ Normal & 101 & $12.0(9.7-14.4)$ & & $5.8(4.0-7.6)$ & \\
\hline \multirow[t]{2}{*}{ Hemoglobin } & \multirow[t]{2}{*}{2 Months } & $<$ Normal & 63 & $9.7(6.7-12.8)$ & \multirow[t]{2}{*}{0.006} & $5.4(3.4-7.4)$ & \multirow[t]{2}{*}{0.024} \\
\hline & & Normal & 45 & $14.6(11.6-17.6)$ & & $8.4(5.8-11.0)$ & \\
\hline \multirow[t]{2}{*}{ Albumin } & \multirow[t]{2}{*}{ Initial } & $<$ Normal & 10 & $3.2(1.1-5.3)$ & \multirow[t]{2}{*}{0.001} & $2.9(0.6-5.2)$ & \multirow[t]{2}{*}{0.050} \\
\hline & & $\geq$ Normal & 76 & $11.7(9.7-13.8)$ & & $5.9(3.6-8.1)$ & \\
\hline \multirow[t]{2}{*}{ LDH } & \multirow[t]{2}{*}{2 Months } & $\leq$ Normal & 35 & $14.6(11.2-18.0)$ & \multirow[t]{2}{*}{0.010} & $6.1(3.8-8.3)$ & \multirow[t]{2}{*}{0.197} \\
\hline & & $>$ Normal & 29 & $9.7(6.1-13.4)$ & & $5.8(0.3-11.3)$ & \\
\hline \multirow[t]{2}{*}{ CRP } & \multirow[t]{2}{*}{2 Months } & $\leq$ Normal & 20 & $14.6(12.4-16.8)$ & \multirow[t]{2}{*}{0.021} & $9.9(3.9-15.9)$ & \multirow[t]{2}{*}{0.007} \\
\hline & & >Normal & 61 & $10.6(7.8-13.3)$ & & $4.4(2.7-6.0)$ & \\
\hline \multirow[t]{2}{*}{ Sodium } & \multirow[t]{2}{*}{ Initial } & $<$ Normal & 11 & $5.2(0.1-11.9)$ & \multirow[t]{2}{*}{0.022} & $2.4(0.9-4.0)$ & \multirow[t]{2}{*}{0.129} \\
\hline & & $\geq$ Normal & 108 & $11.2(8.5-13.9)$ & & $5.7(4.2-7.1)$ & \\
\hline \multirow[t]{4}{*}{ Ca-corr } & \multirow[t]{2}{*}{ Initial } & $\leq 2.40 \mathrm{mmol} / 1$ & 38 & $13.1(9.8-16.4)$ & \multirow[t]{2}{*}{0.017} & $5.0(2.5-7.5)$ & \multirow[t]{2}{*}{0.435} \\
\hline & & $>2.40 \mathrm{mmol} / 1$ & 29 & $7.9(1.8-14.0)$ & & $4.4(0.3-8.4)$ & \\
\hline & \multirow[t]{2}{*}{2 Months } & $\leq 2.39 \mathrm{mmol} / 1$ & 26 & $13.1(9.7-16.4)$ & \multirow[t]{2}{*}{0.001} & $7.0(4.4-9.5)$ & 0.014 \\
\hline & & $>2.39 \mathrm{mmol} / \mathrm{l}$ & 19 & $5.7(2.7-8.6)$ & & $3.3(2.3-4.3)$ & \\
\hline NLR & Initial & $\leq 3.8$ & 60 & $14.2(10.8-17.7)$ & 0.020 & $6.1(3.9-8.2)$ & 0.321 \\
\hline & & $>3.8$ & 60 & $9.2(6.3-12.2)$ & & $4.1(2.5-5.6)$ & \\
\hline PLR & Initial & $\leq 169.1$ & 48 & $14.2(10.7-17.7)$ & 0.014 & $6.6(4.7-8.6)$ & 0.108 \\
\hline & & $>169.1$ & 71 & $9.2(6.4-12.0)$ & & $3.9(2.1-5.6)$ & \\
\hline
\end{tabular}

Ca-corr: Corrected calcium; CI: confidence intervaI; CRP: C-reactive protein; LDH: lactate dehydrogenase; NLR: neutrophil-to-lymphocyte ratio; PLR: platelet-to-lymphocyte ratio.*Log-rank test.

Table V. Overall (OS) and progression-free (PFS) survival after nivolumab treatment initiation according to laboratory parameters (only statistically significant results are shown).

\begin{tabular}{lcccc}
\hline Laboratory parameter & $\mathrm{N}$ & Median OS $(95 \% \mathrm{CI})$, months & $p$-Value* & Median PFS (95\% CI), months \\
\hline Eosinophil count & & & & \\
$\quad$ Decrease/constant & 45 & $9.7(6.0-13.4)$ & 0.029 & $5.9(3.2-8.5)$ \\
Increase & 61 & $12.6(9.9-15.4)$ & & $6.0(4.5-7.4)$ \\
\hline
\end{tabular}

CI: Confidence intervaI. *Log-rank test.

parameters and evaluated the laboratory parameters at the start and after 2 months of treatment (which is a time potentially associated with the radiologically proven relationship to the treatment response prognosis) (26). Our results indicate the possible influence of neutrophils, lymphocytes, NLR, LDH and CRP on PFS or OS. We also assessed these parameters based on cut-offs (under or above normal values) that are easily transferred to other studies and clinical practice. In general, our results verify the possible impact of neutrophils, lymphocytes, LDH and CRP on prognosis or prediction of nivolumab effect. We registered only one statistically significant effect in results that described changes of laboratory parameters, namely changes in eosinophils count, that probably reflect the low relevance of this measurement in clinical practice.

In addition to peripheral blood cell counts, peripheral blood cell count-derived ratios, CRP, LDH and other potential laboratory biomarkers were also evaluated in the present study. Albumin, a negative acute-phase serum protein, is a prognostic biomarker in many solid tumors, including NSCLC (27). Prognostic significance of serum albumin was observed in this study. Moreover, a possible influence of serum albumin on PFS was also noted. Low hemoglobin and hypercalcemia have been found to be associated with poor prognosis across a range of solid tumors (28). Moreover, calcium signaling is also important for immune response (29). In the present study, 
Table VI. Multivariable Cox proportional-hazards model for overall and progression-free survival.

\begin{tabular}{|c|c|c|c|c|c|}
\hline \multirow[b]{2}{*}{ Characteristic } & \multirow[b]{2}{*}{$\mathrm{n}$} & \multicolumn{2}{|c|}{ Overall survival } & \multicolumn{2}{|c|}{ Progression-free survival } \\
\hline & & HR $(95 \%$ CI $)$ & $p$-Value & HR $(95 \%$ CI $)$ & $p$-Value \\
\hline \multicolumn{6}{|l|}{ Number of risk factors } \\
\hline $0-2$ & 22 & 1.00 & - & 1.00 & - \\
\hline $3-4$ & 22 & $2.25(0.80-6.29)$ & 0.123 & $0.75(0.32-1.78)$ & 0.521 \\
\hline$\geq 5$ & 33 & $6.00(2.36-15.28)$ & $<0.001$ & $2.20(1.06-4.56)$ & 0.034 \\
\hline \multicolumn{6}{|l|}{ Gender } \\
\hline Female & 32 & 1.00 & - & 1.00 & - \\
\hline Male & 45 & $0.65(0.30-1.41)$ & 0.278 & $0.80(0.41-1.57)$ & 0.512 \\
\hline \multicolumn{6}{|l|}{ Smoking } \\
\hline Non smoker & 16 & 1.00 & - & 1.00 & - \\
\hline Former smoker & 25 & $0.96(0.35-2.65)$ & 0.933 & $1.41(0.59-3.37)$ & 0.436 \\
\hline Smoker & 36 & $1.16(0.42-3.22)$ & 0.771 & $1.58(0.63-4.01)$ & 0.331 \\
\hline \multicolumn{6}{|l|}{ Histology } \\
\hline Squamous cell carcinoma & 31 & 1.00 & - & 1.00 & - \\
\hline Adenocarcinoma & 46 & $2.23(1.02-4.91)$ & 0.045 & $1.80(0.89-3.64)$ & 0.100 \\
\hline \multicolumn{6}{|c|}{ Age at initiation of nivolumab treatment } \\
\hline$\leq 65$ Years & 29 & 1.00 & - & 1.00 & - \\
\hline$>65$ Years & 48 & $0.66(0.32-1.35)$ & 0.252 & $1.16(0.62-2.18)$ & 0.647 \\
\hline \multicolumn{6}{|c|}{ ECOG PS at initiation of nivolumab treatment } \\
\hline 0 & 14 & 1.00 & - & 1.00 & - \\
\hline 1 & 63 & $1.19(0.46-3.08)$ & 0.727 & $0.78(0.36-1.70)$ & 0.530 \\
\hline \multicolumn{6}{|c|}{ Extent of disease at treatment initiation } \\
\hline III A or III B & 12 & 1.00 & - & 1.00 & - \\
\hline IV & 65 & $2.61(0.94-7.25)$ & 0.065 & $2.28(0.93-5.60)$ & 0.072 \\
\hline \multicolumn{6}{|c|}{ Number of previous treatment lines } \\
\hline 1 & 26 & 1.00 & - & 1.00 & - \\
\hline 2 & 21 & $0.43(0.16-1.18)$ & 0.102 & $0.81(0.39-1.70)$ & 0.580 \\
\hline$\geq 3$ & 30 & $1.20(0.59-2.45)$ & 0.616 & $1.23(0.63-2.39)$ & 0.545 \\
\hline
\end{tabular}

ECOG PS: Eastern Cooperative Oncology Group performance status.

a significantly shorter PFS and OS was evident in patients with lower hemoglobin concentration, with the difference being most marked after 2 months of nivolumab treatment. A lower calcium level corrected for albumin (due to possible impact of albumin on effective calcium concentration) was associated with significantly longer OS and PFS after 2 months of treatment. Elevated potassium may have a negative effect on lymphocyte function (30), but potassium concentration did not affect the efficacy of nivolumab in the present study. A low sodium level is a negative prognostic factor in some tumor types, including NSCLC (31). In the present study, sodium concentration was associated with OS using data with a cut-off, but not in continuous variable data set. Therefore, it is possible that concentrations have no effect on OS above a certain limit (negative result of sodium evaluation as a continuous variable), but only below a certain threshold (positive result using a cut-off value). Hypoglycemia may potentially reduce lymphocyte function (25). In contrast, another study indicated a possible negative effect of hyperglycemia associated with chronic tumor inflammation (32). Thus, the effect, if any, of blood glucose on the efficacy of nivolumab treatment is unclear. Our study did not demonstrate any association of glucose with PFS or OS.

The immune response and inflammatory reaction elicited by the tumor growth can result, depending on context, in both suppression and stimulation of tumor growth. During the past decade, much effort has been focused on the identification of biomarkers that would reflect this delicate balance of host response to tumor growth. Because repeated measurements of peripheral blood cell counts are available for virtually all patients, simple indices derived from these, such as NLR or PLR, have been introduced in retrospective studies. It has been demonstrated in individual studies as well as in meta-analyses that these peripheral blood cell count-derived ratios predict prognosis across a range of solid tumors (33-35). However, this approach has certain limitations for multicentric studies as different methods of differential count determination may result in significant differences in peripheral blood cell countderived ratios (36). The present study also showed an effect of NLR on prognosis of patients treated with nivolumab. Although we observed an association between platelet increase and OS in continuous variable analysis, there was no 

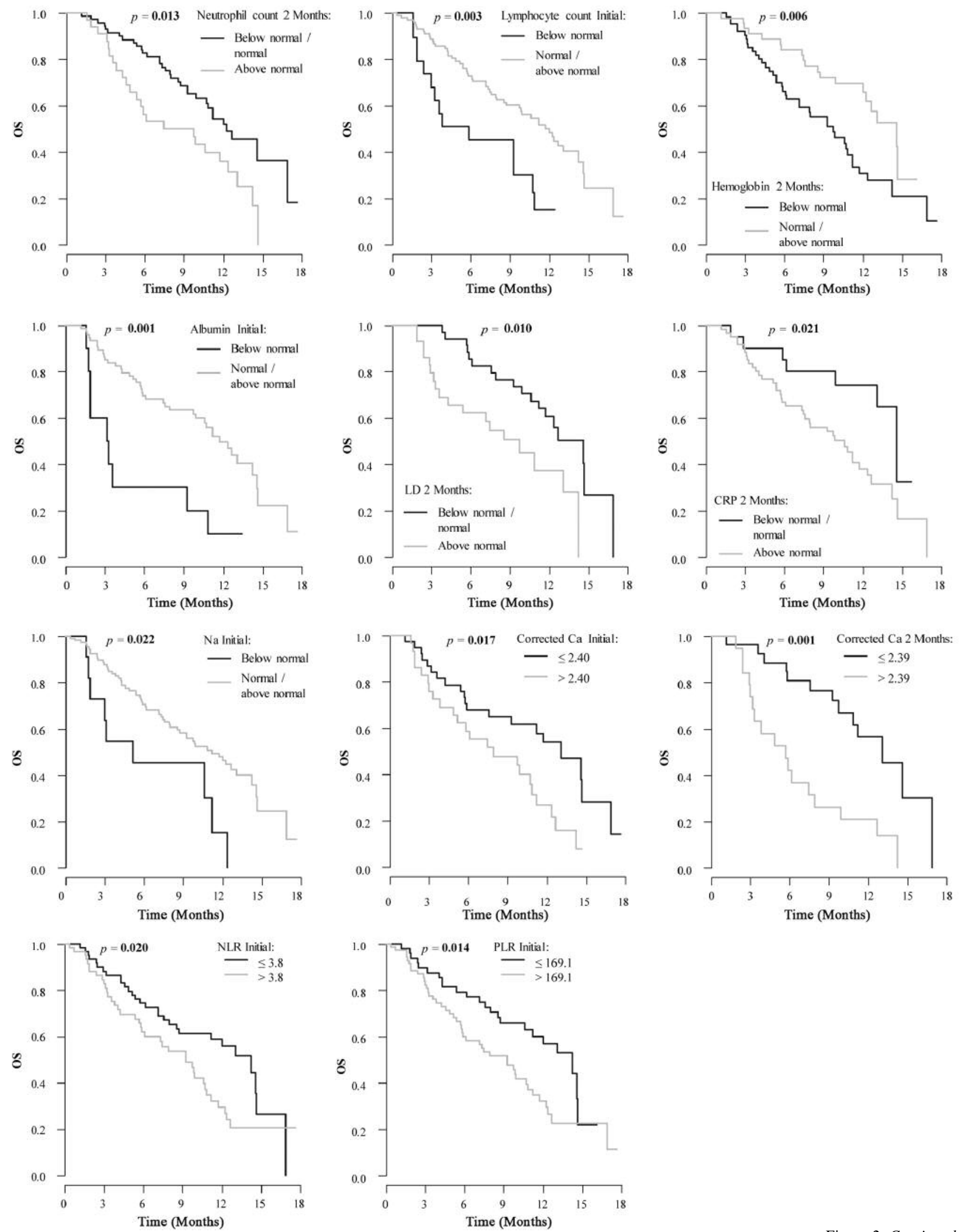

Figure 2. Continued 

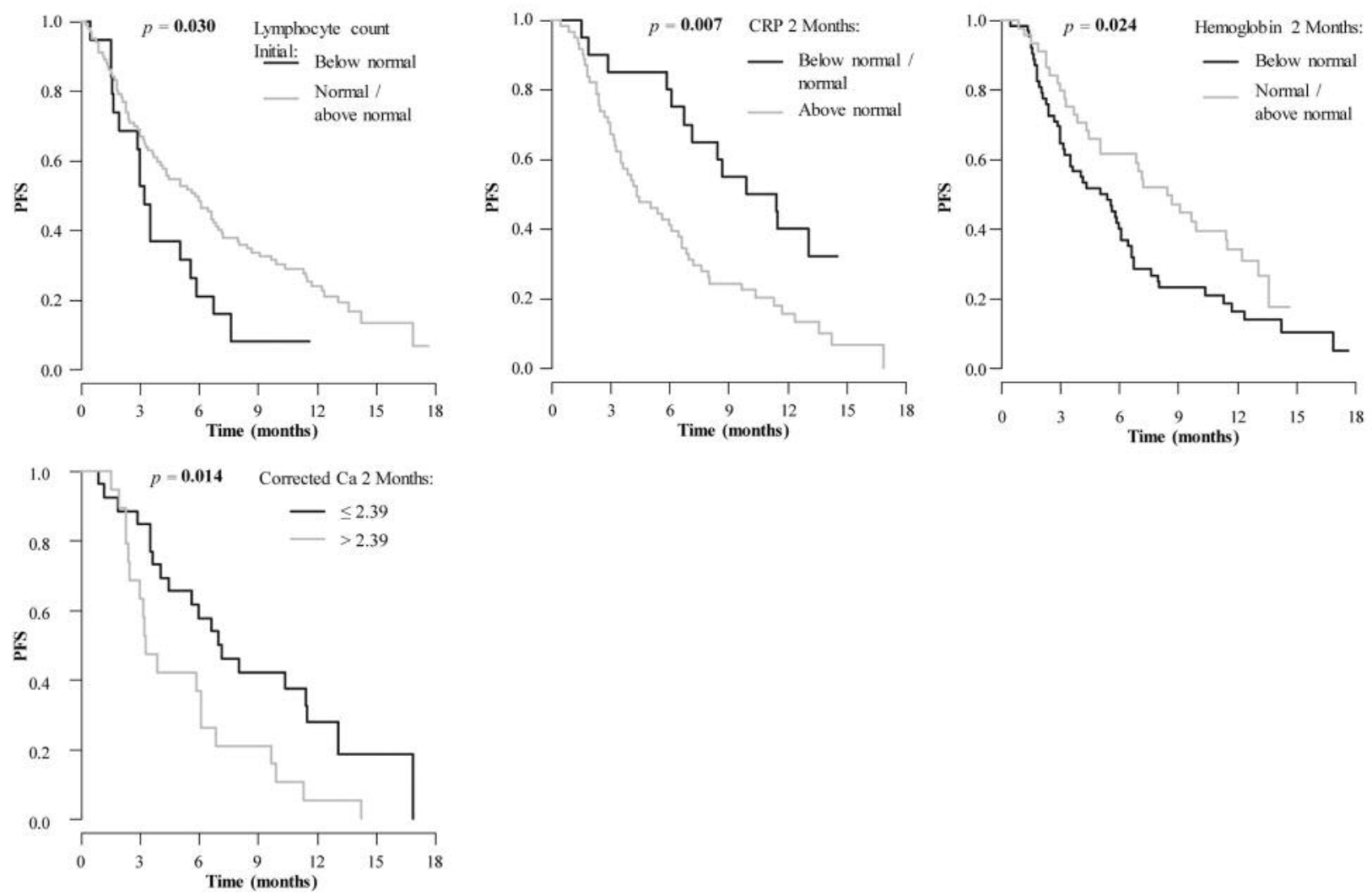

Figure 2. Overall (OS) and progression-free (PFS) survival after nivolumab treatment initiation according to selected laboratory parameters.

effect of PLR on patient prognosis. This is inconsistent with the results when using cut-off values, where increased PLR was associated with shorter OS. More data are, therefore, needed to clarify these discrepancies.

Potential predictive role of an index reflecting chronic inflammation pattern on PFS and OS was examined based on a data set of single laboratory markers. Chronic inflammation is one of the hallmarks of cancer and has a negative impact on patient prognosis $(37,38)$. This inflammatory response may potentially interfere with the effects of immunotherapy (39). The laboratory parameters associated with OS or PFS in the present study reflect molecular pathways of chronic inflammation and were shown to predict prognosis across a range of different tumors (40-45). In the present study, the impact of an index consisting of increased neutrophil count, reduced lymphocyte count, higher NLR, reduced hemoglobin and albumin, and elevated LDH and CRP on the outcome of nivolumab treatment was investigated. We observed a statistically significant effect of this RI on OS and also a significant effect on PFS in both univariate and multivariate analysis.

The present study has several limitations. Firstly, it was a retrospective study of patients from an Extended Access Program that may be biased with regard to patient selection.
Secondly, the majority of patients were not investigated for PD-L1 status (due to no necessity to test the PD-L1 status before using nivolumab), potentially also influencing treatment results for some patients, although at least in patients with squamous cell NSCLC, PD-L1 expression does not predict the efficacy of nivolumab (1). Finally, laboratory parameter data were incomplete and some analyses lacked sufficient statistical power. Thus, the present report should be regarded as exploratory and the results should be verified in a larger prospective study.

In conclusion, in the present retrospective exploratory analysis, tumor histology was the only clinical parameter predicting the outcome of nivolumab treatment. Among the laboratory parameters, the results suggest a potential role for a panel combining selected laboratory parameters that reflect chronic inflammation. The corrected calcium may also affect the efficacy of nivolumab treatment.

\section{Acknowledgements}

This work was supported by grant No. AZV-30748A. Treatment in this study was supported by Bristol Meyer Squibb within Expanded Access Program intended for the Czech Republic. 

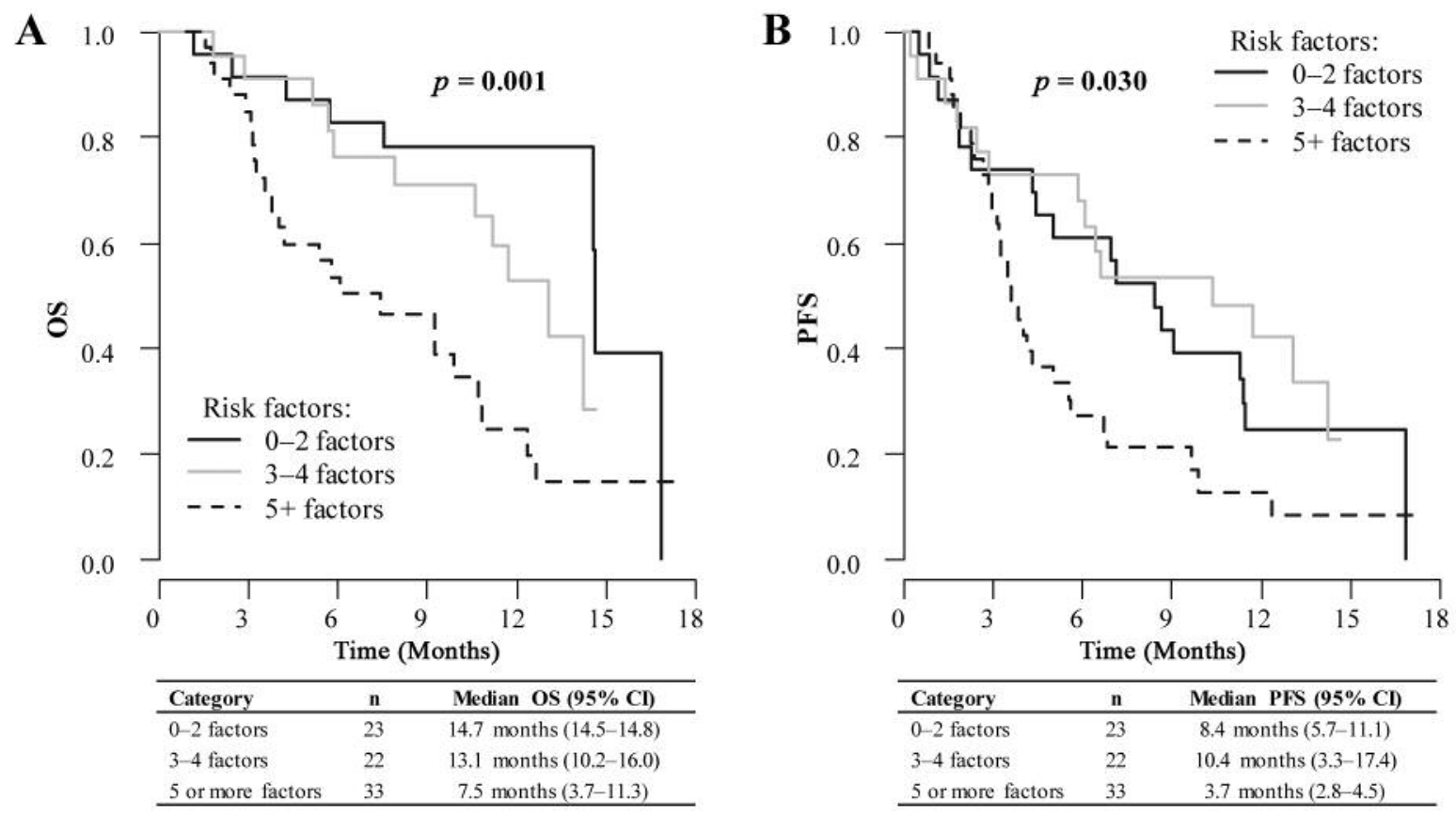

\begin{tabular}{lcc}
\hline Category & n & Median PFS $(\mathbf{9 5} \%$ CI $)$ \\
\hline 0-2 factors & 23 & 8.4 months $(5.7-11.1)$ \\
3-4 factors & 22 & 10.4 months $(3.3-17.4)$ \\
5 or more factors & 33 & 3.7 months $(2.8-4.5)$ \\
\hline
\end{tabular}
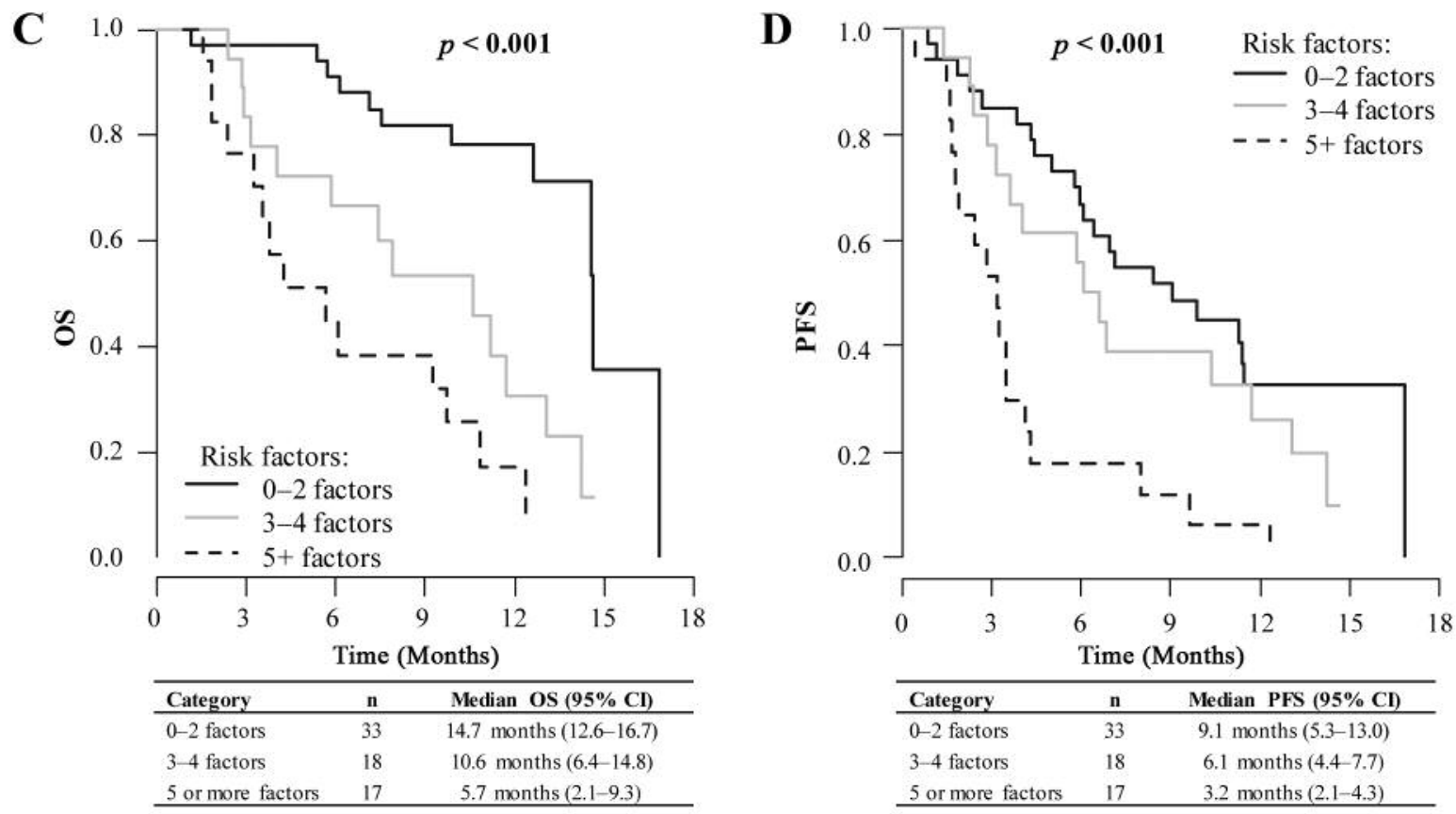

Figure 3. Overall (OS; A and C) and progression-free (PFS; B and D) survival from initiation of nivolumab treatment according to number of risk factors at nivolumab initiation ( $A$ and $B$ ) and after 2 months of treatment $(C$ and $D)$.

\section{References}

1 Brahmer J, Reckamp KL, Baas P, Crinò L, Eberhardt WE, Poddubskaya E, Antonia S, Pluzanski A, Vokes EE, Holgado E, Waterhouse D, Ready N, Gainor J, Arén Frontera O, Havel L, Steins M, Garassino MC, Aerts JG, Domine M, Paz-Ares L, Reck M, Baudelet C, Harbison CT, Lestini B and Spigel DR:
Nivolumab versus docetaxel in advanced squamous-cell nonsmall-cell lung cancer. N Engl J Med 373(2): 123-135, 2015.

2 Borghaei H, Paz-Ares L, Horn L, Spigel DR, Steins M, Ready NE, Chow LQ, Vokes EE, Felip E, Holgado E, Barlesi F, Kohlhäufl M, Arrieta O, Burgio MA, Fayette J, Lena H, Poddubskaya E, Gerber DE, Gettinger SN, Rudin CM, Rizvi N, Crinò L, Blumenschein GR Jr., Antonia SJ, Dorange C, Harbison 
CT, Graf Finckenstein F and Brahmer JR: Nivolumab versus docetaxel in advanced non-squamous non-small-cell lung cancer. N Engl J Med 373(17): 1627-1639, 2015.

3 Takada K, Toyokawa G, Shoji F, Okamoto T and Maehara Y: The significance of the PD-L1 expression in non-small-cell lung cancer: Trenchant double swords as predictive and prognostic markers. Clin Lung Cancer 19(2): 120-129, 2018.

4 Gibney GT, Weiner LM and Atkins MB: Predictive biomarkers for checkpoint inhibitor-based immunotherapy. Lancet Oncol 17(12): e542-e551, 2016.

5 Herbst RS, Baas P, Kim DW, Felip E, Pérez-Gracia JL, Han JY, Molina J, Kim JH, Arvis CD, Ahn MJ, Majem M, Fidler MJ, de Castro G Jr., Garrido M, Lubiniecki GM, Shentu Y, Im E, Dolled-Filhart $M$ and Garon EB: Pembrolizumab versus docetaxel for previously treated, PD-L1-positive, advanced nonsmall-cell lung cancer (KEYNOTE-010): A randomised controlled trial. Lancet 387(10027): 1540-1550, 2016.

6 Kerr KM, Tsao MS, Nicholson AG, Yatabe Y, Wistuba II, Hirsch FR and IASLC Pathology Committee: Programmed death-ligand 1 immunohistochemistry in lung cancer: In what state is this art? J Thorac Oncol 10(7): 985-989, 2015.

7 Voong KR, Feliciano J, Becker D and Levy B: Beyond PD-L1 testing-emerging biomarkers for immunotherapy in non-small cell lung cancer. Ann Transl Med 5(18): 376, 2017.

8 Tanizaki J, Haratani K, Hayashi H, Chiba Y, Nakamura Y, Yonesaka K, Kudo K, Kaneda H, Hasegawa Y, Tanaka K, Takeda $\mathrm{M}$, Ito A and Nakagawa K: Peripheral blood biomarkers associated with clinical outcome in non-small cell lung cancer patients treated with nivolumab. J Thorac Oncol 13(1): 97-105, 2018.

9 Eisenhauer EA, Therasse P, Bogaerts J, Schwartz LH, Sargent D, Ford R, Dancey J, Arbuck S, Gwyther S, Mooney M, Rubinstein L, Shankar L, Dodd L, Kaplan R, Lacombe D and Verweij J: New response evaluation criteria in solid tumours: revised RECIST guideline (version 1.1). Eur J Cancer 45(2): 228-247, 2009.

10 Nosrati A, Tsai KK, Goldinger SM, Tumeh P, Grimes B, Loo K, Algazi AP, Nguyen-Kim TDL, Levesque M, Dummer R, Hamid O and Daud A: Evaluation of clinicopathological factors in PD-1 response: derivation and validation of a prediction scale for response to PD-1 monotherapy. Br J Cancer 116(9): 1141-1147, 2017.

11 Nakamura Y, Kitano S, Takahashi A, Tsutsumida A, Namikawa K, Tanese K, Abe T, Funakoshi T, Yamamoto N, Amagai M and Yamazaki N: Nivolumab for advanced melanoma: pretreatment prognostic factors and early outcome markers during therapy. Oncotarget 7(47): 77404-77415, 2016.

12 Taniguchi Y, Tamiya A, Isa SI, Nakahama K, Okishio K, Shiroyama T, Suzuki H, Inoue T, Tamiya M, Hirashima T, Imamura $\mathrm{F}$ and Atagi $\mathrm{S}$ : Predictive factors for poor progressionfree survival in patients with non-small cell lung cancer treated with nivolumab. Anticancer Res 37(10): 5857-5862, 2017.

13 Kobayashi H, Omori S, Nakashima K, Wakuda K, Ono A, Kenmotsu H, Naito T, Murakami H, Endo M and Takahashi T: Response to the treatment immediately before nivolumab monotherapy may predict clinical response to nivolumab in patients with non-small cell lung cancer. Int J Clin Oncol 22(4): 690-697, 2017.

14 Bagley SJ, Kothari S, Aggarwal C, Bauml JM, Alley EW, Evans TL, Kosteva JA, Ciunci CA, Gabriel PE, Thompson JC, Stonehouse-Lee S, Sherry VE, Gilbert E, Eaby-Sandy B, Mutale F, DiLullo G, Cohen RB, Vachani A nad Langer CJ: Pretreatment neutrophil-to-lymphocyte ratio as a marker of outcomes in nivolumab-treated patients with advanced non-small-cell lung cancer. Lung Cancer 106: 1-7, 2017.

15 Diem S, Schmid S, Krapf M, Flatz L, Born D, Jochum W, Templeton AJ and Früh M: Neutrophil-to-Lymphocyte ratio (NLR) and Platelet-to-Lymphocyte ratio (PLR) as prognostic markers in patients with non-small cell lung cancer (NSCLC) treated with nivolumab. Lung Cancer 111: 176-181, 2017.

16 Oya Y, Yoshida T, Kuroda H, Mikubo M, Kondo C, Shimizu J, Horio Y, Sakao Y, Hida T and Yatabe Y: Predictive clinical parameters for the response of nivolumab in pretreated advanced non-small-cell lung cancer. Oncotarget 8(61): 103117-103128, 2017.

17 Abdel-Rahman O: Smoking and EGFR status may predict outcomes of advanced NSCLC treated with PD-(L)1 inhibitors beyond first line; a meta-analysis. Clin Respir J 12(5): 18091819, 2018.

18 Shien K, Papadimitrakopoulou VA and Wistuba II: Predictive biomarkers of response to PD-1/PD-L1 immune checkpoint inhibitors in non-small cell lung cancer. Lung Cancer 99: 79-87, 2016.

19 Takamori S, Toyokawa G, Takada K, Shoji F, Okamoto T and Maehara Y: Combination therapy of radiotherapy and anti-PD1/PD-L1 treatment in non-Small-cell lung cancer: A mini-review. Clin Lung Cancer 19(1): 12-16, 2018.

20 Melichar B: Laboratory medicine and medical oncology: the tale of two Cinderellas. Clin Chem Lab Med 51(1): 99-112, 2013.

21 Martens A, Wistuba-Hamprecht K, Geukes Foppen M, Yuan J, Postow MA, Wong P, Romano E, Khammari A, Dreno B, Capone M, Ascierto PA, Di Giacomo AM, Maio M, Schilling B, Sucker A, Schadendorf D, Hassel JC, Eigentler TK, Martus P, Wolchok JD, Blank C, Pawelec G, Garbe C and Weide B: Baseline peripheral blood biomarkers associated with clinical outcome of advanced melanoma patients treated with ipilimumab. Clin Cancer Res 22(12): 2908-2918, 2016.

22 Hopkins AM, Rowland A, Kichenadasse G, Wiese MD, Gurney $\mathrm{H}$, McKinnon RA, Karapetis CS and Sorich MJ: Predicting response and toxicity to immune checkpoint inhibitors using routinely available blood and clinical markers. Br J Cancer 117(7): 913-920, 2017.

23 Friedman CF and Postow MA: Emerging tissue and blood-based biomarkers that may predict response to immune checkpoint inhibition. Curr Oncol Rep 18(4): 21, 2016.

24 Ferrucci PF, Gandini S, Cocorocchio E, Pala L, Baldini F, Mosconi M, Antonini Cappellini GC, Albertazzi E and Martinoli $\mathrm{C}$ : Baseline relative eosinophil count as a predictive biomarker for ipilimumab treatment in advanced melanoma. Oncotarget 8(45): 79809-79815, 2017.

25 Blank CU, Haanen JB, Ribas A and Schumacher TN: Cancer immunology. The "cancer immunogram". Science 352(6286): 658-660, 2016.

26 Nishino M, Dahlberg SE, Adeni AE, Lydon CA, Hatabu H, Jänne PA, Hodi FS and Awad MM: Tumor response dynamics of advanced non-small cell lung cancer patients treated with PD1 inhibitors: Imaging markers for treatment outcome. Clin Cancer Res 23(19): 5737-5744, 2017.

27 Fiala O, Pesek M, Finek J, Racek J, Minarik M, Benesova L, Bortlicek Z, Sorejs O, Kucera R and Topolcan O: Serum albumin is a strong predictor of survival in patients with advanced-stage non-small cell lung cancer treated with erlotinib. Neoplasma 63(3): 471-476, 2016. 
28 Yuasa T, Masuda H, Yamamoto S, Numao $\mathrm{N}$ and Yonese $\mathrm{J}$ : Biomarkers to predict prognosis and response to checkpoint inhibitors. Int J Clin Oncol 22(4): 629-634, 2017.

29 Rooke R: Can calcium signaling be harnessed for cancer immunotherapy? Biochim Biophys Acta 1843(10): 2334-2340, 2014.

30 Eil R, Vodnala SK, Clever D, Klebanoff CA, Sukumar M, Pan JH, Palmer DC, Gros A, Yamamoto TN, Patel SJ, Guittard GC, Yu Z, Carbonaro V, Okkenhaug K, Schrump DS, Linehan WM, Roychoudhuri R and Restifo NP: Ionic immune suppression within the tumour microenvironment limits T-cell effector function. Nature 537(7621): 539-543, 2016.

31 Fiordoliva I, Meletani T, Baleani MG, Rinaldi S, Savini A, Di Pietro Paolo $\mathrm{M}$ and Berardi R: Managing hyponatremia in lung cancer: latest evidence and clinical implications. Ther Adv Med Oncol 9(11): 711-719, 2017.

32 Chang SC and Yang WV: Hyperglycemia, tumorigenesis, and chronic inflammation. Crit Rev Oncol Hematol 108: 146-153, 2016.

33 Melichar B, Hruzova K, Krcmova L, Javorska L, Peskova E, Solichova D, Hyspler R, Malirova E, Vosmik M, Bartouskova M, Klos D, Studentova H: Association of peripheral blood cell count-derived ratios, biomarkers of inflammatory response and tumor growth with outcome in previously treated metastatic colorectal carcinoma patients receiving cetuximab. Pteridines 28(3-4): 221-232, 2017.

34 Templeton AJ, McNamara MG, Seruga B, Vera-Badillo FE, Aneja P, Ocaña A, Leibowitz-Amit R, Sonpavde G, Knox JJ, Tran B, Tannock IF and Amir E: Prognostic role of neutrophilto-lymphocyte ratio in solid tumors: A systematic review and meta-analysis. J Natl Cancer Inst 106(6): dju124, 2014.

35 Templeton AJ, Ace O, McNamara MG, Al-Mubarak M, VeraBadillo FE, Hermanns T, Seruga B, Ocaña A, Tannock IF and Amir E: Prognostic role of platelet to lymphocyte ratio in solid tumors: a systematic review and meta-analysis. Cancer Epidemiol Biomarkers Prev 23(7): 1204-1212, 2014.

36 Studentova H, Vitaskova D, Sramek V, Indrakova J, Adam T, Juranova J, Petrova P, Kujovska Krcmarova L, Peskova E, Solichtova D, Kalabova H and Melichar B: Correlationsofneutrophil-to-lymphocyte, lymphocyte-to-monote and plateletto-lymphocyteratioswithbiomarkersofatherosclerosis risk and inflammatory response in patientswith a historyofbreastcancer. Pteridines 26: 161-172, 2015.
37 Aggarwal BB and Gehlot P: Inflammation and cancer: how friendly is the relationship for cancer patients? Curr Opin Pharmacol 9(4): 351-369, 2009.

38 Vendramini-Costa DB and Carvalho JE: Molecular link mechanisms between inflammation and cancer. Curr Pharm Des; 18(26): 3831-3852, 2012.

39 Willumsen N, Thomsen LB, Bager CL, Jensen C and Karsdal MA: Quantification of altered tissue turnover in a liquid biopsy: a proposed precision medicine tool to assess chronic inflammation and desmoplasia associated with a pro-cancerous niche and response to immuno-therapeutic anti-tumor modalities. Cancer Immunol Immunother 67(1): 1-12, 2016.

40 Fuchs D, Hausen A, Reibnegger G, Werner ER, WernerFelmayer G, Dierich MP and Wachter H: Immune activation and the anaemia associated with chronic inflammatory disorders. Eur J Haematol 46(2): 65-70, 1991.

41 McMillan DC: Systemic inflammation, nutritional status and survival in patients with cancer. Curr Opin Clin Nutr Metab Care 12(3): 223-226, 2009.

42 Di Stefano G, Manerba M, Di Ianni L and Fiume L: Lactate dehydrogenase inhibition: exploring possible applications beyond cancer treatment. Future Med Chem 8(6): 713-725, 2016.

43 Park SJ and Shin JI: Inflammation and hyponatremia: an underrecognized condition? Korean J Pediatr 56(12): 519-522, 2013.

44 Brenner DR, Scherer D, Muir K, Schildkraut J, Boffetta P, Spitz MR, Le Marchand L, Chan AT, Goode EL, Ulrich CM and Hung $\mathrm{RJ}$ : A review of the application of inflammatory biomarkers in epidemiologic cancer research. Cancer Epidemiol Biomarkers Prev 23(9): 1729-1751, 2014.

45 McMillan DC: The systemic inflammation-based Glasgow Prognostic Score: a decade of experience in patients with cancer. Cancer Treat Rev 39(5): 534-540, 2013.
Received October 24, 2018

Revised November 3, 2018

Accepted November 8, 2018 